\title{
Clinical Characteristics and Treatment Outcomes of 293 COVID-19 Patients Admitted to the Intensive Care Unit of a Tertiary Care Hospital of Eastern India
}

\author{
Deependra K Rai ${ }^{1} \odot$, Nishant Sahay ${ }^{\oplus}$, Pallavi Lohani ${ }^{3} \odot$
}

\begin{abstract}
Objectives of the study: The objectives of the study were to assess the mortality among critically ill coronavirus disease (COVID) patients and to look at the factors which could have a bearing on mortality of these patients presenting to our designated tertiary COVID care institute. Method: This was a retrospective observational study involving all adult patients admitted to our intensive care unit (ICU) with coronavirus disease-2019 (COVID-19) infection between June 30,2020, and August 31, 2020. We compared patient-related factors and laboratory test results among all survivors vs nonsurvivors in our ICU with an aim to predict the factors which could predict increased risks of mortality among sick patients admitted to our ICU.

Results and conclusion: The overall ICU mortality in our ICU during the study period was $76.69 \%$ and less than $5 \%$ of the patients requiring mechanical ventilation within 1 day of admission, survived. More than half of the deaths (54.66\%) occurred within 5 days of ICU admission. The best predictors for mortality based upon the Cox proportional hazard ratio are increasing age, neutrophilia, increased D-dimer, prolonged stay in ICU for 1-2 weeks, and those requiring mechanical ventilation. Patients with one or more comorbidities were noted to have $16 \%$ of higher risk of death than those without any comorbidity.

Keywords: Coronavirus disease-2019, Intensive care unit, Mortality, Predictors.

Indian Journal of Critical Care Medicine (2021): 10.5005/jp-journals-10071-24048
\end{abstract}

\section{INTRODUCTION}

Severe acute respiratory syndrome coronavirus 2 (SARS-CoV-2) has disrupted life since December 2019. ${ }^{1}$ It has resulted in millions of deaths even in India. However, data on intensive care mortality in the Indian population has been sparse. ${ }^{2}$ Clinical spectrum of SARS-CoV-2 infection ranges from asymptomatic or mild, self-limiting respiratory tract disease to severe progressive pneumonia leading to acute respiratory distress syndrome and death. The proportion of patients with severe illness requiring admission to an intensive care unit (ICU) has been reported to be between 4 and $32 \% .^{3}$ This figure is dependent upon the state of healthcare facilities available to the citizens. There have been a number of studies that have characterized these critically ill coronavirus disease-2019 (COVID-19) patients from various countries like China, Italy, and United Kingdom. ${ }^{4-6}$ In the Indian context, especially in resource-limited settings, understanding demographic patterns of such sick patients and factors related to important clinical outcomes becomes essential. Realizing that there are little data and inadequate mortality assessments in a COVID-19 Indian ICU setting, we embarked upon this study to describe clinical characteristics, outcomes, and factors associated with mortality in patients with COVID-19 requiring intensive care in a tertiary care hospital in Bihar, with very limited resources.

The primary objective of the study was to assess mortality among critically ill COVID patients, and we also looked for factors that could have a bearing on mortality of these patients presenting to our designated tertiary COVID care institute.
${ }^{1}$ Department of Pulmonary Medicine, All India Institute of Medical Sciences, Patna, Bihar, India

${ }^{2}$ Department of Anesthesiology, All India Institute of Medical Sciences, Patna, Bihar, India

${ }^{3}$ Department of CFM, All India Institute of Medical Sciences, Patna, Bihar, India

Corresponding Author: Deependra K Rai, Department of Pulmonary Medicine, All India Institute of Medical Sciences, Patna, Bihar, India, Phone: +91 7764981421, e-mail: drdeependrak@ aiimspatna.org

How to cite this article: Rai DK, Sahay N, Lohani P. Clinical Characteristics and Treatment Outcomes of 293 COVID-19 Patients Admitted to the Intensive Care Unit of a Tertiary Care Hospital of Eastern India. Indian J Crit Care Med 2021;25(12):1395-1401.

Source of support: Nil

Conflict of interest: None

\section{Materials and Methods}

This was a single-center, record-based, retrospective observational analytical study involving all adult patients admitted to the ICU with COVID-19 infection between June 30, 2020, and August 31, 2020. After approval of the ethics committee, records of all patients admitted to the intensive care unit of our hospital were collected from the Medical Records Department. Two postgraduate residents collected all data in a predesigned pro forma from patient records present in the Medical Records Department. The data

(c) The Author(s). 2021 Open Access This article is distributed under the terms of the Creative Commons Attribution 4.0 International License (https://creativecommons. org/licenses/by-nc/4.0/), which permits unrestricted use, distribution, and non-commercial reproduction in any medium, provided you give appropriate credit to the original author(s) and the source, provide a link to the Creative Commons license, and indicate if changes were made. The Creative Commons Public Domain Dedication waiver (http://creativecommons.org/publicdomain/zero/1.0/) applies to the data made available in this article, unless otherwise stated. 
were then reviewed and validated by two faculties from different departments before analysis.

\section{Data Collection}

We retrieved the demographic information, exposure history, duration, and nature of the clinical symptoms, comorbidities, laboratory test results, details of treatment provided, length of ICU stay, complications, and outcomes of all patients presenting to our ICU during the study period.

Following laboratory investigation reports were analyzed: complete blood counts, blood sugar levels, prothrombin time, international normalized ratio (INR), D-dimer, C-reactive protein (CRP), procalcitonin, and serum ferritin.

\section{Statistical Analysis}

The continuous variables were expressed as mean or median with interquartile range (IQR) and the comparison between groups was analyzed by Student's $t$-test and Mann-Whitney $U$ test, respectively. The categorical variables were presented in percentage (\%) and the comparison between them was done using Chi-squared or Fisher's exact test. Statistical significance was defined as $p<0.05$. The analysis was carried out using SPSS 20.0. In the survival analysis, outcome was either dead or alive. The time to event like death was calculated from the time of admission. The logrank test for equality of survivor function was used to identify the individual predictor variables. Kaplan-Meier curve for survival probabilities was plotted for significant variables against time to death. Kaplan-Meier curve was plotted and compared for different parameters. Multivariable Cox proportional hazard model was formulated using significant predictors assessed in logrank test for categorical variable and Cox proportional hazard regression for continuous variable.

\section{Results}

A total of 965 adult patients with COVID-19 infection were admitted to the hospital during the study period. Of these, 293 (30.36\%) patients were severely sick and needed admission into the ICU. Admission criteria were as per discretion of the treating intensivists. Overall all-cause mortality in the ICU was noted to be $76.69 \%$ (Flowchart 1). Mean age of patients admitted to the ICU was 57.63 years. In patients who succumbed to the disease mean age was found to be significantly higher as compared to the survivors (60.01 vs 49.73 years) $(p<0.05)$. Patients more than 60 years old formed a majority of patients who required intensive care (44.71\%).

Of all patients needing intensive care, $70.3 \%$ of the patients had at least one comorbidity. Diabetes and hypertension (HTn) were most commonly noted (44.02\% each). Chronic kidney disease (CKD) (9.90\%), coronary artery disease (CAD) (8.53\%), chronic obstructive pulmonary disease (COPD)/asthma (5.46\%), hypothyroidism (9.89\%), and various malignancies (2.38\%) were the other comorbidities noted (Table 1). Presence of a comorbidity was noted to be significantly higher in nonsurvivors vs those who survived $(75.55$ vs $44.11 \%, p<0.05)$.

Comparing the laboratory parameters on admission, white blood cell counts and neutrophil counts were found to be significantly higher in nonsurvivors. Biochemical parameters like blood urea, serum creatinine, lactate dehydrogenase (LDH), C-CRP, ferritin, and D-dimer levels were noted to be higher in the deceased group. Blood hemoglobin levels, absolute lymphocyte count, and serum calcium were found to be significantly lower in nonsurvivors $(p<0.05)$ (Table 2).
A total of $24.11 \%$ of severely ill patients needed mechanical ventilation on admission, $35.15 \%$ of the patients were managed on noninvasive ventilation, and the rest on other forms of oxygen therapy. These included high-flow nasal oxygen, nonreservoir mask, simple face mask, or even nasal prong.

Among the patients that required invasive mechanical ventilation on admission, mortality was $95.89 \%$. Analyzing the age distribution of patients who succumbed to the disease, more than half (52\%) were 60 years or older. Forty out of the 73 patients who needed invasive ventilation were greater than 60 years of age. The mean duration of ICU stay was $6.32 \pm 4.95$ days and it was significantly lower in deceased group. Most mortality in our ICU occurred within 5 days of admission.

Multivariable Cox proportional hazard model was formulated to predict the risk of death among COVID-19 patients admitted to ICU. The significant predictors of death were noted to be neutrophilia, increased D-dimer, duration of ICU stay for 1-2 weeks, and those patients requiring mechanical ventilation within 24 hours of admission. Increasing age was associated with 1.02 times higher risk of dying. Although insignificant, those patients with one or more comorbidities were noted to have $16 \%$ of higher risk of death than those without any comorbidity. Analyzing the comorbidities, patients with asthma had $73 \%$ of higher risk of fatal outcome. Certain inflammatory markers were also noted to have a significantly higher hazard ratio for mortality such as D-dimer $(p<0.00)$ and neutrophil count $>80 \%(p=0.002)$. Lymphocyte count $>20 \%$ was found to be protective. Such patients were $10 \%$ less likely to succumb to disease. Among the treatment outcomes, ICU stay for 1-2 weeks had a significantly higher risk of death. Similarly, duration of mechanical ventilation $>7$ days increased the chances of death by $20 \%$ (Table 3 ).

Figure 1 depicts the comparison of survival probabilities of COVID-19, on the basis of differences in distribution of age and various blood parameters using Kaplan-Meier survival curve. The $\mathrm{Y}$-axis shows the survival probability, whereas $\mathrm{X}$-axis represents time to death (in days). The median survival time decreased with increase in age, serum creatinine more than one, and neutrophilia. The logrank test was run to test the significance of equality of survival function and we noted that all the factors were found to be highly significant $(<0.00)$ except the neutrophil-lymphocyte ratio (NLR) $(p=0.078)$.

Figure 2 depicts the median survival of the COVID-19 patients with comorbidity using Kaplan-Meier curve. As shown in Figure 1, $\mathrm{Y}$-axis presents survival probability, whereas $\mathrm{X}$-axis presents time to death (in days). As it is very much evident from the graph that the survival curve for patients without comorbidity is above the curve for patients with comorbidity in all the graphs, the median

Flowchart 1: Flow diagram of study patients

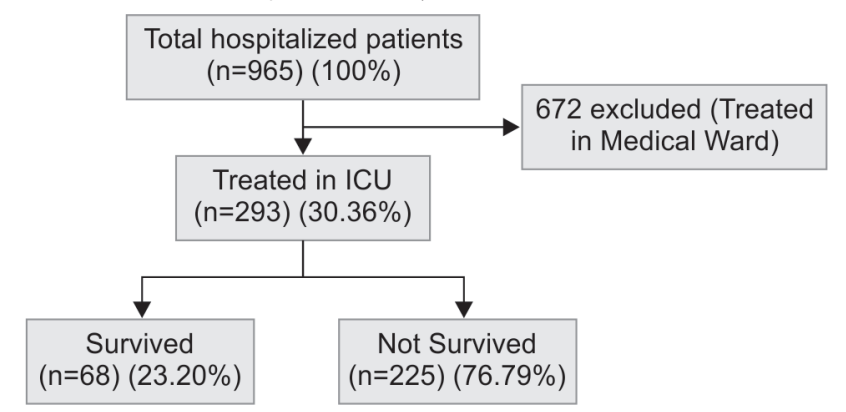


Treatment Outcomes of COVID-19 Patients Admitted to ICU

Table 1: Clinicodemographic characteristics of COVID patients admitted to ICU

\begin{tabular}{|c|c|c|c|c|}
\hline Variable & $\begin{array}{c}\text { Total } \\
(n=293)(\%)\end{array}$ & $\begin{array}{c}\text { Deceased } \\
(n=225)(76.79)\end{array}$ & $\begin{array}{c}\text { Survived } \\
(n=68)(23.20 \%)\end{array}$ & $p$ value \\
\hline Age & $57.63 \pm 14.14$ & $60.01 \pm 14.28$ & $49.73 \pm 14.14$ & \\
\hline$<20$ & 01 & 00 & $01(100)$ & $<0.00$ \\
\hline $21-30$ & 09 & $04(44.44)$ & $5(55.56)$ & \\
\hline $31-40$ & 27 & $15(55.56)$ & $12(44.44)$ & \\
\hline $41-50$ & 48 & $33(68.75)$ & $15(31.25)$ & \\
\hline $51-60$ & 77 & $56(72.73)$ & $21(27.27)$ & \\
\hline$>60$ & 131 & $117(89.31)$ & $14(10.69)$ & \\
\hline $\begin{array}{l}\text { Gender } \\
\text { Male } \\
\text { Female }\end{array}$ & $\begin{array}{c}233 \\
60\end{array}$ & $\begin{array}{r}179(79.55) \\
46(20.44)\end{array}$ & $\begin{array}{l}54(79.41) \\
14(20.59)\end{array}$ & 0.979 \\
\hline \multicolumn{5}{|l|}{ Comorbidities } \\
\hline At least one comorbidity (+) & $206(70.30)$ & $170(75.55)$ & $36(44.11)$ & \\
\hline Diabetes & 129 & $109(84.50)$ & $20(15.50)$ & 0.006 \\
\hline $\mathrm{HTn}$ & 129 & $112(86.82)$ & $17(13.18)$ & $<0.00$ \\
\hline CKD & 29 & $28(96.55)$ & $01(3.45)$ & 0.005 \\
\hline CAD & 25 & $20(80.00)$ & $05(20.00)$ & 0.691 \\
\hline COPD/asthma & 16 & $15(93.75)$ & $01(6.25)$ & 0.130 \\
\hline Hypothyroidism & 29 & $23(79.31)$ & $06(20.69)$ & 0.735 \\
\hline Malignancy & 07 & $06(85.71)$ & $01(14.29)$ & 0.571 \\
\hline Duration in ICU (days) & $6.32 \pm 4.95$ & $5.84 \pm 4.0$ & $7.89 \pm 5.56$ & 0.0003 \\
\hline$<1$ day & 05 & $01(0.4)$ & $04(5.88)$ & \\
\hline $1-5$ & 148 & $123(54.66)$ & $25(36.76)$ & \\
\hline $6-10$ & 93 & 76 (33.77) & $17(25)$ & \\
\hline $11-15$ & 34 & $18(8)$ & $16(23.52)$ & \\
\hline $16-20$ & 09 & $03(1.33)$ & $06(8.82)$ & \\
\hline$>20$ days & 04 & $03(1.33)$ & 01 (1.47) & \\
\hline
\end{tabular}

CKD, chronic kidney disease; CAD, coronary artery disease; ICU, intensive care unit

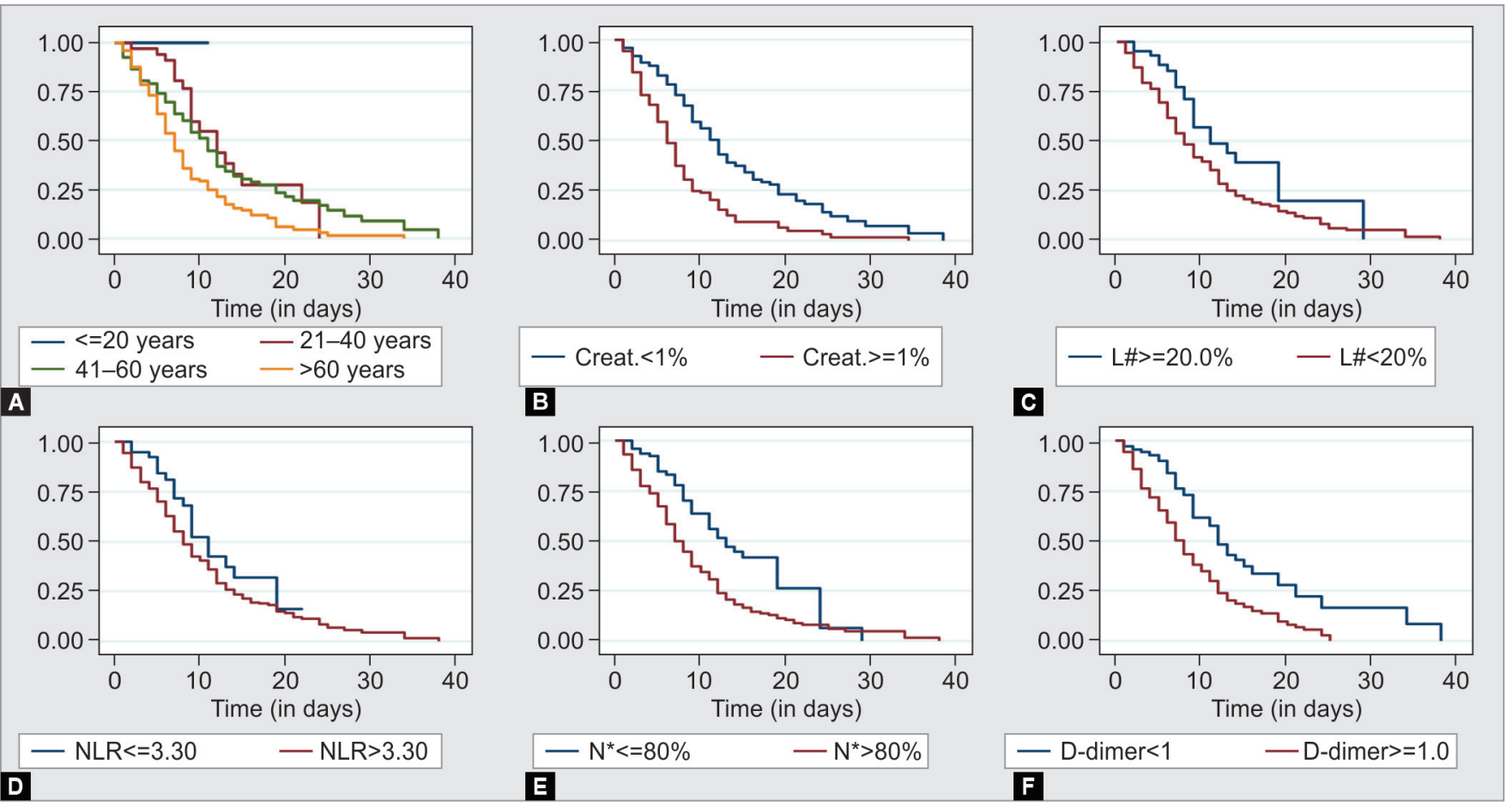

Figs 1 A to F: Kaplan-Meier curve showing differences in survival probabilities of COVID-19 patients on the basis of distribution of age and blood parameters 
Table 2: Laboratory results on admission

\begin{tabular}{|c|c|c|c|c|}
\hline & $\begin{array}{c}\text { Total }(n=293) \\
\text { Mean }( \pm S D)\end{array}$ & $\begin{array}{l}\text { Deceased } \\
(n=225)\end{array}$ & $\begin{array}{l}\text { Survived } \\
(n=68)\end{array}$ & $p$ value \\
\hline Hemoglobin & $11.49 \pm 5.06$ & $10.95 \pm 2.22$ & $12.08 \pm 1.50$ & 0.0001 \\
\hline TLC & $12.83 \pm 7.68$ & $14.11 \pm 8.13$ & $8.65 \pm 3.59$ & $<0.00$ \\
\hline Platelet count & $210.66 \pm 111.36$ & $208.97 \pm 115.39$ & $216.26 \pm 97.44$ & 0.6369 \\
\hline Neutrophil & $83.40 \pm 14.99$ & $85.52 \pm 14.53$ & $76.43 \pm 14.46$ & $<0.00$ \\
\hline Lymphocyte & $12.27 \pm 12.12$ & $10.35 \pm 11.76$ & $18.63 \pm 11.19$ & $<0.00$ \\
\hline$N L R>3.3$ & 251 (85.67) & 203 (80.88) & 48 (19.12) & $<0.00$ \\
\hline Eosinophil & $0.41 \pm 0.90$ & $0.29 \pm 0.72$ & $0.80 \pm 1.26$ & $<0.00$ \\
\hline SGOT & $103.08 \pm 281.54$ & $113.49 \pm 313.53$ & $68.80 \pm 53.74$ & 0.2524 \\
\hline SGPT & $89.44 \pm 110.225$ & $91.43 \pm 119.02$ & $83.34 \pm 74.13$ & 0.5968 \\
\hline Total bilirubin & $1.88 \pm 1.17$ & $1.27 \pm 1.31$ & $0.19 \pm 0.36$ & 0.0268 \\
\hline Direct bilirubin & $0.45 \pm 0.57$ & $0.50 \pm 0.64$ & $0.32 \pm 0.11$ & 0.0235 \\
\hline Alk. phos. & $120.79 \pm 92.11$ & $128.46 \pm 100.41$ & $94.23 \pm 54.79$ & 0.0069 \\
\hline Total protein & $6.49 \pm 1.03$ & $6.35 \pm 1.07$ & $7.04 \pm 0.66$ & $<0.00$ \\
\hline S. albumin & $3.28 \pm 0.57$ & $3.15 \pm 0.55$ & $3.73 \pm 0.41$ & $<0.00$ \\
\hline Globulin & $3.22 \pm 0.57$ & $3.19 \pm 0.6$ & $3.30 \pm 0.47$ & 0.1779 \\
\hline Blood urea & $75.95 \pm 73.95$ & $80.05 \pm 78.27$ & $35.91 \pm 35.12$ & $<0.00$ \\
\hline Creatinine & $1.65 \pm 2.02$ & $1.89 \pm 2.25$ & $0.85 \pm 0.49$ & $<0.00$ \\
\hline Sodium & $139.22 \pm 73.45$ & $141.58 \pm 83.73$ & $134.39 \pm 5.60$ & 0.4802 \\
\hline Potassium & $4.46 \pm 0.86$ & $4.49 \pm 0.89$ & $4.35 \pm 0.71$ & 0.2402 \\
\hline Calcium & $8.32 \pm 0.97$ & $8.19 \pm 1.03$ & $8.77 \pm 0.52$ & 0.002 \\
\hline CRP & $\begin{array}{c}132.13 \pm 119.0 \\
(n=180)\end{array}$ & $\begin{array}{c}145.83 \pm 132.21 \\
(n=149)\end{array}$ & $\begin{array}{c}62.52 \pm 65.87 \\
(n=31)\end{array}$ & 0.0008 \\
\hline Ferritin & $\begin{array}{c}963.47 \pm 980.06 \\
(n=205)\end{array}$ & $\begin{array}{c}1061.86 \pm 1128.57 \\
(n=164)\end{array}$ & $\begin{array}{c}569.92 \pm 440.84 \\
\quad(n=41)\end{array}$ & 0.0068 \\
\hline LDH & $\begin{array}{c}1240.55 \pm 812.86 \\
(n=149)\end{array}$ & $\begin{array}{c}1336.10 \pm 771.24 \\
(n=122)\end{array}$ & $\begin{array}{c}808.79 \pm 285.69 \\
(n=27)\end{array}$ & 0.0006 \\
\hline D-dimer & $\begin{array}{c}4.06 \pm 10.63 \\
(n=213)\end{array}$ & $\begin{array}{c}5.33 \pm 13.63 \\
(n=164)\end{array}$ & $\begin{array}{c}1.91 \pm 3.97 \\
(n=49)\end{array}$ & 0.0844 \\
\hline PT & $\begin{array}{c}14.97 \pm 8.16 \\
(n=234)\end{array}$ & $\begin{array}{c}15.16 \pm 7.82 \\
(n=191)\end{array}$ & $\begin{array}{c}14.15 \pm 8.73 \\
(n=43)\end{array}$ & 0.451 \\
\hline INR & $\begin{array}{c}1.21 \pm 1.05 \\
(n=234)\end{array}$ & $\begin{array}{c}1.23 \pm 1.11 \\
(n=191)\end{array}$ & $\begin{array}{c}1.10 \pm 0.77 \\
(n=43)\end{array}$ & 0.432 \\
\hline
\end{tabular}

CRP, C-reactive protein; PT, prothrombin time; INR, international normalized ratio

Table 3: Hazard ratio for the fatal outcomes among COVID-19 ICU patients $(N=213)(p<0.00)$

\begin{tabular}{lc}
\hline Factors & $\begin{array}{c}\text { Mortality among COVID-19 patients } \\
\text { Hazard ratio, (95\% CI) p value }\end{array}$ \\
\hline Age & $1.01(0.998-1.025), 0.086$ \\
Comorbidities & $1.73(0.952-3.129), 0.072$ \\
Asthma & $1.16(0.794-1.694), 0.443$ \\
One or more comorbidities & \\
Inflammatory markers & $2.19(1.287-3.740), 0.002$ \\
Neutrophilia (neutrophils $>80 \%)$ & $0.89(0.418-1.916), 0.776$ \\
Lymphopenia (lymphocytes $<20 \%)$ & $2.00(1.385-2.891),<0.000$ \\
D-dimer $>1.00$ & \\
Treatment outcomes & \\
Duration in ICU (7-14 days) & $2.05(1.219-3.452), 0.007$ \\
Duration on mechanical ventilation $(>7$ days) & $1.18(1.059-1.299), 0.001$ \\
\hline
\end{tabular}

Multivariable Cox proportional hazard model was formulated to predict the risk of death among COVID-19 patients admitted to ICU. The model is highly significant $\left(\mathrm{X}^{2}=60.16, \mathrm{df}=08, p<0.000\right)$ 

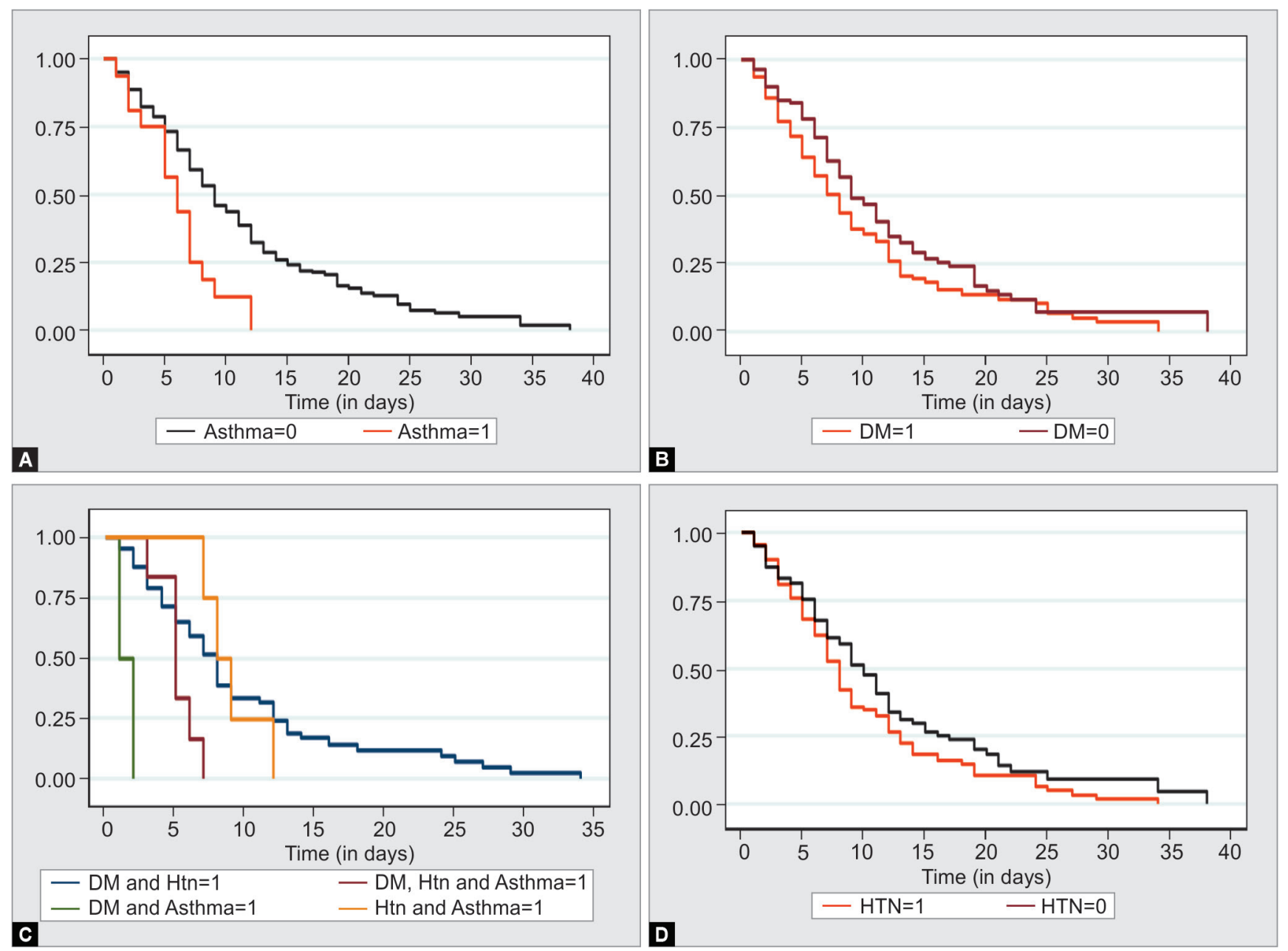

Figs 2A to D: Kaplan-Meier curve showing differences in survival probabilities in COVID-19 patients with comorbidity (DM, diabetes mellitus; HTn, hypertension)

survival of patients without any comorbidity was 9 days, whereas that for patients with asthma, diabetes mellitus, and HTn was 6, 8 , and 8 days, respectively. With more than one comorbidity, the survival probability decreased further. There were eight patients with both DM and asthma and they had a low median survival of only 5 days. Similarly, those with HTn and asthma (10 patients) had 6 days, followed by 7 days of median survival for diabetes and HTn (72 patients). Among the six patients with HTn, DM, and asthma, median survival period was only 5 days. Survival curve for DM, asthma, and HTn was plotted only because these comorbidities were found to be significant on logrank test for equality of survivor function $(p<0.00)(2 . c)$.

\section{Discussion}

Our hospital is one of only three dedicated tertiary COVID care centers in the state that caters to a population of more than 131 million people. There are only about 3,000 beds for all COVID patients. Many times, there is a significant disease progression in patients before they are able to find a bed for themselves. In our study, we noted that almost $30.36 \%$ of hospitalized COVID patients required intensive care which is similar to data reported by some other big hospitals. Jorge Cedano and colleagues found $29 \%$ of hospitalized patients required intensive care which corroborates with data from the US Centers for Disease Control and Prevention. ${ }^{7,8}$ While planning a number of ICU beds in a hospital, this may be taken into consideration.

Most of the patients admitted to our ICU were males aged more than 60 years of age with a mean age of 57 years. Age group of patients admitted to ICU varies across studies. A similar age-group distribution as ours has been reported by NamendysSilva et al., ${ }^{9}$ whereas some other studies have reported slightly higher mean age of admitted patients. ${ }^{5,10-13}$ Patients who succumbed were significantly older compared to those who survived [(60.01 \pm 14.28 year) vs $(49.73 \pm 14.14) ; p<0.001]$. This finding has been noted earlier in other studies (Table 1). ${ }^{9-11}$ There was no difference in survival rates between the two genders. However, a finding of note was a markedly higher proportion of males presenting to our institute compared to women. There were 233 males and only 60 females admitted to our ICU during the study period. Either females are more resistant to COVID multiorgan failure in the general population or it could be due to the patriarchal nature of society in these parts of the country. However, mortality after admission into the ICU was similar in both genders.

All-cause mortality in our ICU during the study period was $76.69 \%$ which is slightly higher compared to $69 \%$ reported by Jorge Cedano et al. ${ }^{7}$ Mortality varies across geographical regions and 
from country to country. Literature reveals wide variations in the ICU mortality rates, ranging from $16.7 \%$ in 24 patients in India in one study to $84.6 \%$ in 13 patients in the USA in another. ${ }^{2,5,9-13}$ These are very small samples compared to our studied cohort of 293 patients. Analysis of ICU mortality especially in the Indian context is difficult to find in literature. A systemic review reported overall mortality to range between 30 and $40 \% .{ }^{14}$ There may be many reasons for varying mortality rates. A nonstandardized ICU admission criterion can have a significant bearing on outcomes. Availability of trained manpower and adequate resources, e.g., specialized nephrology care, dialysis services, and availability of ECMO, all affect mortality.

Most mortality in our setup was found in a subgroup of patients who needed mechanical ventilation during their stay in the ICU (95.89\%). Other authors have also reported high mortality rates between 86 and $97 \%$ among patients put on mechanical ventilation, ${ }^{15,16}$ whereas some other studies showed lower mortality rates of less than $30 \% .{ }^{5,9,10}$ Mortality rates of patients on mechanical ventilation in our study are also high. Some of the reasons could be that our institute caters to a huge population of a very backward area of the country. Our institute is among the very few tertiary care centers available in the state and thus many of the patients who presented to our ICU were referred from other ICUs of the state. As our healthcare systems were stretched, patients were not able to get supportive treatment, as the number of patients requiring intensive care overwhelmed all available medical infrastructure in the state of Bihar, India. Most of the patients presenting even to the non-ICU areas were very sick. Consequently, institution of mechanical ventilation could have been delayed in many patients resulting in poorer prognosis.

Patients in our ICU stayed for a mean duration of $6.32 \pm 4.95$ days, which is 5 days lesser than that reported in some previous studies. ${ }^{5,9,10}$ This was significantly lower in deceased group compared to those who survived. We noted that maximum deaths in our ICU occurred between 1st and 5th days of admission and most of these patients had been having symptoms for 6-10 days before getting admission at our institute.

Among the laboratory markers, the NLR and among the inflammatory markers, LDH, CRP, and serum ferritin were noted to be higher among the nonsurvivors. Similar results have been reported in earlier studies. ${ }^{17,18} \mathrm{D}$-dimer levels were also raised in nonsurvivors, but it was not found to be statistically significant similar to the report of Rodelo et al. ${ }^{19}$

Multivariable Cox proportional hazard model was formulated to predict the risk of death among COVID-19 patients admitted to ICU. Increasing age was associated with 1.02 times higher risk of dying.

Although insignificant, those patients with one or more comorbidities had a $16 \%$ of higher risk of death than those without comorbidity. Significant predictors of death were prolonged stay in ICU for 1-2 weeks and requirements of mechanical ventilation.

Strengths of our study include its relatively large sample size and first-of-its-kind study from this region that highlights characteristics and outcomes of COVID-19 patients admitted to an ICU of a tertiary care institute of Eastern India.

This study has certain limitations. Being a single-center study, it has some limits to represent the general population. Like other observational studies, it is subject to confounding and associations between exposures. Outcomes may not be interpreted as causal relationships. Comparison of morbidity and mortality in any ICU depends heavily upon the ICU admission criteria. These are likely to vary between institutions and at different time points during the pandemic. Finally, researchers were not blinded during data collection and chart reviews.

\section{Conclusion}

- The overall ICU mortality was $76.69 \%$ in COVID-19 infection and less than $5 \%$ requiring mechanical ventilation within 1 day of admission survived.

- More than half of deaths (54.66\%) occurred within the 5 th day of ICU admission.

- The best predictors for mortality in the Cox proportional hazard ratio are increasing age, neutrophilia, increased D-dimer, stay in ICU for 1-2 weeks, and requiring mechanical ventilation.

\section{ORCID}

Deependra K Rai @ https://orcid.org/0000-0001-9090-8124

Nishant Sahay 이 https://orcid.org/0000-0001-8297-5538

Pallavi Lohani i] https://orcid.org/0000-0002-2105-6674

\section{References}

1. Wu Z, McGoogan JM. Characteristics of and important lessons from the coronavirus disease 2019 (COVID-19) outbreak in China: summary of a report of 72314 cases from the Chinese Center for Disease Control and Prevention. JAMA 2020;323(13):1239-1242. DOI: 10.1001/ jama.2020.2648.

2. Shukla U, Chavali S, Mukta P, Mapari A, Vyas A. Initial experience of critically ill patients with COVID-19 in Western India: a case series. Indian J Crit Care Med 2020;24(7):509-513. DOI: 10.5005/ jp-journals-10071-23477.

3. Aziz S, Arabi YM, Alhazzani W, Evans L, Citerio G, Fischkoff K, et al. Managing ICU surge during the COVID-19 crisis: rapid guidelines. Intens Care Med 2020;46(7):1303-1325. DOI: 10.1007/s00134-02006092-5.

4. Yang $X, Y u Y, X u J$, Shu H, Xia J, Liu H, et al. Clinical course and outcomes of critically ill patients with SARS-CoV-2 pneumonia in Wuhan, China: a single-centered, retrospective, observational study. Lancet Respir Med 2020;8(5):475-481. DOI: 10.1016/S2213-2600(20)30079-5.

5. Grasselli G, Zangrillo A, Zanella A, Antonelli M, Cabrini L, Castelli A, et al. Baseline characteristics and outcomes of 1591 patients infected with SARS-CoV-2 admitted to ICUs of the Lombardy Region, Italy. JAMA 2020;323(16):1574. DOI: 10.1001/jama.2020.5394.

6. Cummings $M J$, Baldwin MR, Abrams D, Jacobson SD, Meyer BJ, Balough EM, et al. Epidemiology, clinical course, and outcomes of critically ill adults with COVID-19 in New York City: a prospective cohort study. Lancet 2020;395(10239):1763-1770. DOI: 10.1016/S01406736(20)31189-2.

7. Cedano J, Fabian Corona E, Gonzalez-Lara M, Santana M, Younes I, Ayad S, et al. Characteristics and outcomes of patients with COVID-19 in an intensive care unit of a community hospital; retrospective cohort study. J Community Hosp Intern Med Perspect 2021;11(1):27-32. DOI: 10.1080/20009666.2020.1830516.

8. National Center for Immunization and Respiratory Diseases (NCIRD). Cases in the U.S. Centers for Disease Control and Prevention 2020. Available from:www.cdc.gov/coronavirus/2019-ncov/cases-updates/ cases-in-us.html.

9. Ñamendys-Silva SA, Alvarado-Ávila PE, Domínguez-Cherit G, Rivero-Sigarroa E, Sánchez-Hurtado LA, et al. Mexico COVID-19 Critical Care Collaborative Group. Outcomes of patients with COVID-19 in the intensive care unit in Mexico: a multicenter observational study. Heart Lung 2021;50(1):28-32. DOI: 10.1016/j.hrtlng.2020.10.013.

10. Oliveira E, Parikh A, Lopez-Ruiz A, Carrilo M, Goldberg J, Cearras M, et al. ICU outcomes and survival in patients with severe COVID-19 in the largest health care system in central Florida. PLoS One 2021;16(3):e0249038. DOI: 10.1371/journal.pone.0249038. 
11. Thomson RJ, Hunter J, Dutton J, Schneider J, Khosravi M, Casement A, et al. Clinical characteristics and outcomes of critically ill patients with COVID-19 admitted to an intensive care unit in London: a prospective observational cohort study. PLoS One 2020;15(12):e0243710. DOI: 10.1371/journal.pone.0243710.

12. Larsson E, Brattström O, Agvald-Öhman C, Grip J, Campoccia Jalde F, Strålin K, et al. Characteristics and outcomes of patients with COVID-19 admitted to ICU in a tertiary hospital in Stockholm, Sweden. Acta Anaesthesiol Scand 2021;65(1):76-81. DOI: 10.1111/aas.13694.

13. Arentz M, Yim E, Klaff L, Lokhandwala S, Riedo FX, Chong M, et al. Characteristics and outcomes of 21 critically ill patients with COVID-19 in Washington State. JAMA 2020;323(16):1612-1614. DOI: 10.1001/jama.2020.4326.

14. Armstrong RA, Kane AD, Kursumovic E, Oglesby FC, Cook TM. Mortality in patients admitted to intensive care with COVID-19: an updated systematic review and meta-analysis of observational studies. Anaesthesia 2021;76(4):537-548. DOI: 10.1111/anae.15425.

15. Wu C, Chen X, Cai Y, Zhou X, Xu S, Huang H, et al. Risk factors associated with acute respiratory distress syndrome and death in patients with coronavirus disease 2019 pneumonia in Wuhan, China. JAMA Intern Med 2020;180(7):934-943. DOI: 10.1001/ jamainternmed.2020.0994.

16. Zhou F, Yu T, Du R, Fan G, Liu Y, Liu Z, et al. Clinical course and risk factors for mortality of adult inpatients with COVID-19 in Wuhan, China: a retrospective cohort study. Lancet 2020;395(10229): 1054-1062. DOI: 10.1016/S0140-6736(20)30566-3.

17. Herold T, Jurinovic V, Arnreich C, Lipworth BJ, Hellmuth JC, von Bergwelt-Baildon M, et al. Elevated levels of IL- 6 and CRP predict the need for mechanical ventilation in COVID-19. J Allergy Clin Immunol 2020;146(1):128-136. DOI: 10.1016/j.jaci.2020.05.008.

18. Smeeth $L$, Thomas SL, Hall AJ, Hubbard R, Farrington $P$, Vallance $P$. Risk of myocardial infarction and stroke after acute infection or vaccination. N Engl J Med 2004;351(25):2611-2618. DOI: 10.1056/ NEJMoa041747.

19. Rodelo JR, De la Rosa G, Valencia ML, Ospina S, Arango CM, Gómez $\mathrm{Cl}$, et al. D-dimer is a significant prognostic factor in patients with suspected infection and sepsis. Am J Emerg Med 2012;30(9): 1991-1999. DOI: 10.1016/j.ajem.2012.04.033. 